\title{
nature
}

biotechnology

\section{Members need only apply}

\author{
Few of Europe's struggling young biotechs are likely to benefit from the latest $€ 107$ (\$154) million tranche of \\ Innovative Medicines Initiative (IMI) funding.
}

ast week, the $€ 2$ ( $\$ 2.8$ ) billion IMI formally launched its fourth call for L proposals. Expressions of interest are sought from not only academics and patient, nonprofit or intergovernmental organizations, but also small- to medium-sized enterprises (SMEs). Indeed, one of IMI's stated goals is "boosting the biopharmaceutical sector in Europe." And yet it is clear that the scope and direction of IMI's projects are oriented to the pharmaceutical industry, with Europe's R\&D-intensive life sciences SMEs an afterthought at best.

IMI arose as a result of extended discussions between the European Commission's research directorate and the EFPIA (the European Federation of Pharmaceutical Industry Associations). From the start, the initiative's challenge was to find politically acceptable common ground between the overarching economic aims of the European Commission and the commercial ambitions of the pharmaceutical industry.

EFPIA represents a mixture of major multinational pharmaceutical companies along with some regional and national European players. Many of the member companies of the EFPIA associations are involved in individual European Commission research programs, but EFPIA's research directors, as a group, had not been involved closely with the European Union before IMI. The problem for EFPIA was to agree upon an IMI research agenda that its members could sign up to. Ultimately, the decision was to focus on research challenges shared across the industry where pooling resources would be more productive than keeping them proprietary-so-called precompetitive research.

The Commission, for its part, was driven by the need to forge a single European market and to promote European competitiveness in a range of industrial areas, especially in pharmaceuticals where Europe has historical strengths. It also had a remit to promote R\&D within industry-as a result of the Lisbon summit of March 2000-but could not put money directly into single-company projects so as not to favor the economy of the country within which the single company was based. Neither could it direct money to profitable businesses unless those businesses matched the Commission's contribution with money of their own.

That these two political and industrial behemoths managed to create IMI-a solution acceptable to both-was in itself a substantial achievement. Indeed, if measured in terms of number of participants and funded projects, IMI has had success. In June, a press release trumpeted that 23 projects are underway, involving a total of 21 EFPIA member companies, 103 academic teams, 23 SMEs and 2 patient organizations.

But whether these consortia truly engage innovative biotech remains less clear. A closer look at individual projects reveals that partnering SMEs are almost exclusively service companies or contract research organizations (CROs). For example, all four SMEs (Molecular Networks, Inteligand, Chemotargets and Lead Molecular Design) involved in the eTOX consortium, which looks at in silico toxicological data, are service companies/CROs developing specific software solutions. In another consortium, SAFE-T, which looks at drug-induced toxicities in people, one SME (Firalis) does do R\&D on biomarkers, but the others include a CRO (Experimental and Diagnostic Immunology) and a consultancy firm (Interface Europe) dedicated "to successfully develop and manage European projects and...funding programmes dedicated to research, innovation and training for European competitiveness."

Such companies are not the types of SMEs one would have thought would be central to IMI's aim of "shaping the current and future research and development of innovative drugs in Europe."

One reason for the poor engagement of biotechs is intellectual property (IP). Although the Commission drew up extensive explanatory documentation distinguishing background (pre-consortium) and foreground (during consortium) IP and defining the various rights of participants to its access, use or dissemination, the fact is that IP is the most important tangible asset for most venture-backed biotech firms.

An innovative biotech grows by developing a smart technology and selling it many times over to a range of partners, or developing different varieties of the same $\mathrm{R} \& \mathrm{D}$ product and selling each variety to a different customer. IMI, in contrast, effectively rounds up all the potential (pharma) buyers of a technology and gives them access to the technology at bargain basement rates, albeit with a carrot of some development funding.

The result is that what should be a market-driven, inter-company, competitive bidding process for a technology asset becomes, through IMI, a one-time sale to a pharma buyers' club spanning the whole market. A small company in an IMI consortium risks having its IP accessed by all its potential customers. And the risk for companies that do not participate when IMI projects cover their field of interest may be worse-IMI might fund an alternative route to the same end, potentially undermining their competitive edge.

It can even be argued that IMI is undermining the already precarious edifice of European venture-backed biotech. Any early-stage investor thinking of backing companies developing stem cell methods of drug discovery, for instance, could be forgiven for hesitating if they knew that $€ 26$ (\$37) million of public money was being targeted into that area (precisely the sum in that area in last month's fourth call for proposals).

Thus, SME engagement in IMI is a clear weakness. The initiative's leadership should be clear in communicating that the long-term agenda and specific projects in each IMI call are predetermined by an inner cabal of EFPIA members at pharmaceutical companies, which are large corporations with their own business imperatives and conservatism with respect to research directions.

IMI has done wonders to spur collaborations between academia and big pharma in translational research. But it needs to do more to engage biotech SMEs so that they can play a greater role in agenda setting. If these concerns are not addressed, IMI will likely do as much to stymie European biotech and innovation as help European pharma. 